\title{
A Life-Course Perspective on Migration and Integration
}

\author{
Edited by M. Wingens, M. Windzio, H. de Valk, and C. Aybek
}

\author{
Claudia Diehl
}

Published online: 11 November 2011

(C) The Author(s) 2011. This article is published with open access at Springerlink.com

\begin{abstract}
"A Life-Course Perspective on Migration and Integration" is an edited volume that compiles a number of articles on immigrants' integration. It is an ambitious book whose main goal is to demonstrate that the life course approach is a useful paradigm for this research field that has so far not received the attention it deserves. In order to show this, the editors start out with an introductory chapter on the basic assumptions of the life course perspective. In doing so, they delimit the approach by arguing that, on the one hand, it means more than micro-analytical research with longitudinal data and that, on the other hand, it is applicable to a much broader set of phenomena than those of interest to demographers alone.
\end{abstract}

Based on this, Wingens and coauthors have compiled 11 chapters that tackle the issue of immigrant integration. This part of the book brings together a broad range of scholars working empirically on this issue. Most chapters focus on Germany but some compare the German situation with that of France (Tucci) or Israel (Kogan et al.), while others look at other European countries such as Austria (Latcheva and Herzog-Punzenberger) or the UK (Muttarak). Substantively, the structural integration of migrants in the educational system and the labor market and their family patterns rank most prominently in the volume, supplemented by chapters on identification, residential segregation, and transnational activities. Methodologically, quantitative and qualitative methods are used, though the former clearly dominate, using panel and longitudinal data as well as cross-sectional data from international, national or local research projects. The affinity to the life course paradigm varies between the chapters. Some of them, the contributions by Windzio, de Valk, Söhn, or Schunck, for example, follow the theoretical imperatives raised in the introduction more closely than others. Schunck shows in his SOEP-based analysis on transnational activities that the latter are partly dependent on migrants' financial resources, but that this relationship varies with increasing duration of stay.

C. Diehl $(\bowtie)$

University of Göttingen, Göttingen, Germany

e-mail: cdiehl@gwdg.de 
Other chapters, such as the one by Kogan et al., start out from a more "classical" micro-analytic perspective, asking about the role of group-specific reception contexts and taking into account individual resources acquired before immigration. Again others, for example the study by Latechva and Herzog-Punzenberger, address life phases more explicitly and make heavy use of "life course terminology" but it remains unclear in what regard their results extend beyond existing findings of integration research.

In the concluding chapter, the editors elaborate on the relationship between life course and integration research by specifying the theoretical implications of the former: most importantly, the study of integration as a process rather than a state, the consideration of agency as well as structural conditions, and the investigation of generational change and changes over time. Based on this, they review the preceding articles and discuss how these take the basic principle of the life course perspective into account.

Unlike many edited books, this volume has a clear theoretical message and a visible red thread. The basic argument is that, almost by nature, integration research calls for a life course perspective given this field's genuine interest in the consequences of migration as a fundamental "transition" and its long-lasting impact over time and across generations. One might add that this argument is sometimes even taken too far, for example when the editors claim that "by dynamically relating decision-making at the micro-level to social structures and institutions at the mesoor macro- level this approach avoids individualistic as well as ecological reductionism" (p. 294). In fact, the above-mentioned theoretical imperatives are indispensable for any sort of explanatory empirical integration research. Fundamental research questions of this substantive area of interest cannot be answered otherwise: Why do some groups integrate faster than others? Why do ethnic ties and identifications foster structural integration for some groups but hamper it for others? What role do social distances and discriminations play in accounting for groupspecific adaptation patterns?

In this regard, one wants to subscribe to all statements on what effective integration research should do-including the argument that the life course approach is a "set of theoretical guidelines rather than a unified theory" (p. 288). The fact that these guidelines are often ignored or not sufficiently taken into account might, however, have less to do with the absence of an explicit life course perspective than with the tremendous data requirements of such an approach: up-todate, comparative, longitudinal data on minority and majority members, ideally supplemented by qualitative studies, are still hard to find. In sum, the volume does a good job in showing that the life course approach is something between a helpful reminder of the theoretical principles that should guide empirical integration research and a magic bullet for those interested in the topic.

Open Access This article is distributed under the terms of the Creative Commons Attribution Noncommercial License which permits any noncommercial use, distribution, and reproduction in any medium, provided the original author(s) and source are credited. 